Supplement of Atmos. Chem. Phys., 15, 8559-8576, 2015

http://www.atmos-chem-phys.net/15/8559/2015/

doi:10.5194/acp-15-8559-2015-supplement

(C) Author(s) 2015. CC Attribution 3.0 License.

(c) (i)

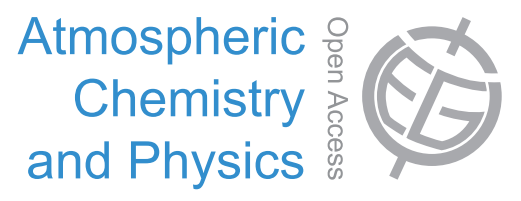

Supplement of

\title{
Relationships between photosynthesis and formaldehyde as a probe of iso- prene emission
}

\section{Y. Zheng et al.}

Correspondence to: Y. Zheng (yiqi.zheng@yale.edu)

The copyright of individual parts of the supplement might differ from the CC-BY 3.0 licence. 


\section{Supplementary materials}

3 S1. Comparison of observationally-derived and simulated GPP and tropospheric

4 HCHO columns

6 In Figure S1, we compare the simulated GPP averaged in each season (second column)

7 with the observational-derived GPP from FLUXNET (first column), and the differences

8 are shown in the third column. The simulated GPP in three model runs Y-PS, Y-MEGAN

9 and Y-MEGAN-SM are identical. The model consistently overestimates GPP in the

10 southeast US. The annual and summertime relative differences are $24 \%$ and $16 \%$,

11 respectively. In the Amazon, the simulated GPP is always lower than the FLUXNET-

12 derived GPP. The differences in each season are: $-1.5,-2.3,-3.1$ and $-1.8 \mathrm{~g}[\mathrm{C}] \mathrm{m}^{-2}$ day $^{-1}$

13 and the relative difference of annual mean GPP is $-30 \%$. The model underestimates GPP

14 in most NH boreal regions in MAM and JJA. Globally, the model simulates a total GPP

15 flux of $116.7 \mathrm{Pg}[\mathrm{C}]$ year $^{-1}$, which is $10 \%$ lower than the FLUXNET-derived GPP (129.6

$16 \operatorname{Pg}[\mathrm{C}]$ year $\left.^{-1}\right)$.

18 The simulated $\mathrm{HCHO}$ columns are considerably higher than the OMI-retrieved HCHO by

19 about a factor of 2 (Figure S2). This discrepancy is a result of the large uncertainties in

20 both the satellite $\mathrm{HCHO}$ retrieval and the HCHO chemistry in the model. In Figure S2,

21 OMI-a, OMI-b and OMI-c represent OMI-retrieved HCHO based on the AMFs of Y-PS,

22 Y-MEGAN and Y-MEGAN-SM, respectively. The models' seasonal averaged spatial

23 patterns are similar. Thus, Figure S2 shows only OMI-a with Y-PS simulated HCHO 
1 columns. HCHO columns from OMI and from the models show similar spatial patterns

2 and seasonality in the low- and mid-latitudes. In NH high-latitudes, the satellite-based

3 HCHO columns show an opposite seasonality pattern compared to the models, i.e. higher

4 in winter and lower in summer, which might be unrealistic due to retrieval bias under

5 light-limited conditions (De Smedt et al., 2008; Wittrock et al., 1997).

\section{S2. Meteorological drivers of GPP and HCHOv in NASA ModelE2-YIBs}

9 We apply simulated monthly data of GPP and HCHOv from NASA ModelE2-YIBs in

10 nine model years to investigate their meteorological drivers. Fig. S3 and Fig. S4 show the

11 multiple linear regression (MLR) results for monthly mean GPP and HCHOv against $\mathrm{T}_{\mathrm{s}}$,

12 PAR (SW for HCHOv) and P. In the three simulations Y-PS, Y-MEGAN and Y-

13 MEGAN-SM, MLR of GPP results are exactly the same; MLR of HCHOv results only

14 show minor differences. Therefore we only show MLR results using Y-PS isoprene

15 algorithm as a representative in Fig. S3 and S4. The standardized partial regression

16 coefficients of GPP and HCHOv associated with $\mathrm{T}_{\mathrm{s}}$, PAR (SW for HCHOv) and P are

17 denoted by GPP_ $\beta \_T_{s}, G P P \_\beta \_P A R, G P P \_\beta \_P$ and HCHOv_ $\beta \_T_{s}, H C H O v \_\beta \_S W$,

18 HCHOv_ $\beta \_$P. The regionally averaged $\beta$-coefficients are summarized in Table S1

19 including all three simulations.

21 As in Fig. S3, the MLR of simulated GPP reproduces main observational patterns from

22 FLUXNET-GPP successfully but with some non-consistencies: (1) GPP is strongly

23 positively related to $\mathrm{T}_{\mathrm{s}}$ in the NH springtime and summertime high-latitudes, and is 
1 anticorrelated in tropics and summertime $\mathrm{NH}$ mid-latitudes when $\mathrm{T}_{\mathrm{s}}$ values approach or

2 exceed the photosynthetic thermal optimum. The model overestimates this anticorrelation

3 with $T_{\mathrm{s}}$ especially in the tropics: in the Amazon simulated GPP_ $\beta \_T_{\mathrm{s}}=-0.13,-0.18$ and -

40.41 in MAM, JJA and SON (Table S1); but observational GPP $\_\_T_{\mathrm{s}}=0.11,0.14$ and

$5 \quad 0.24$, respectively (Table 2). This is most probably due to its bias in meteorology: e.g.

6 Amazonian $\mathrm{T}_{\mathrm{s}}$ in the model is about $2 \sim 3^{\circ} \mathrm{C}$ higher than in the MERRA reanalysis (Table

7 1), and is always higher than the thermal optimum $25^{\circ} \mathrm{C}$. (2) GPP is overall positively

8 related to PAR, while the simulated negative relationship with PAR in NH high-latitudes

9 might be problematic. (3) The relationship between GPP and precipitation is always

10 positive, especially in the tropics in MAM and SON (in the Amazon GPP_ $\beta \_P=0.41$,

11 0.11, and 0.28 in MAM, JJA and SON).

13 In Fig. S4, the MLR of simulated HCHOv shows smoother pattern than observational

14 results of OMI-retrieved $\mathrm{HCHO}$. The covariance of simulated $\mathrm{HCHOv}$ with $\mathrm{T}_{\mathrm{s}}$ and $\mathrm{SW}$

15 are much stronger than the covariance with P. Simulated HCHOv is strongly positively

16 related to $T_{s}$ because increasing temperature promotes isoprene emission and oxidation to

17 HCHO, except in some regions with hardly any precursors (e.g. Tibet Plateau and

18 Sahara) where increasing temperature accelerates the chemical destruction of HCHO.

19 The sensitivity to $T_{s}$ decreases when $T_{s}$ gets relatively high (e.g. in the tropics and in

20 summertime NH mid-latitudes). Similarly, it's clear in Fig. S4 that light facilitates both

$21 \mathrm{HCHO}$ formation and destruction: in most regions $\mathrm{HCHOv}$ is negatively related to $\mathrm{SW}$ in

22 MAM and SON, and is weakly correlated with SW in JJA. The role of $\mathrm{P}$ in influencing

$23 \mathrm{HCHOv}$ is much weaker than $\mathrm{T}_{\mathrm{s}}$ and $\mathrm{SW}$ in NASA ModelE2-YIBs. 
1 Table S1. Regionally averaged MLR $\beta$-coefficients with standard deviation for simulated

2 GPP and HCHOv from NASA ModelE2-YIBs in the southeast US, defined as [31 to

$335^{\circ} \mathrm{N} ;-94$ to $\left.-79^{\circ} \mathrm{E}\right]$ and the Amazon defined as $\left[-15^{\circ} \mathrm{S}\right.$ to $3^{\circ} \mathrm{N},-76^{\circ}$ to $\left.-54^{\circ} \mathrm{E}\right]$. The

4 covariance of GPP with $\mathrm{T}_{\mathrm{s}}, \mathrm{PAR}$ and precipitation $(\mathrm{P})$ are denoted as GPP_ $\beta \mathrm{T}_{\mathrm{s}}$,

5 GPP_ $\beta \_$PAR, GPP_ $\beta \_P$; the covariance of $\mathrm{HCHOv}$ with $\mathrm{T}_{\mathrm{s}}, \mathrm{SW}$ and precipitation $(\mathrm{P})$ are

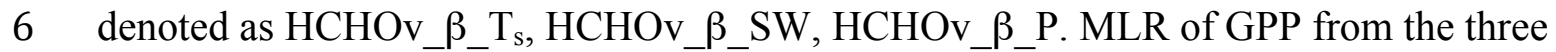

7 simulations Y-PS, Y-MEGAN and Y-MEGAN-SM are exactly the same; MLR of

$8 \mathrm{HCHOv}$ from the three simulations are listed as (a), (b) and (c) in this table.

\section{Southeast US}

\section{MLR of model GPP}

\begin{tabular}{|c|c|c|c|}
\hline & GPP_ $\beta \_T_{s}$ & GPP_ $\beta$ _PAR & GPP_ $\beta \_P$ \\
\hline МАМ & $0.77 \pm 0.19$ & $0.18 \pm 0.12$ & $0.11 \pm 0.09$ \\
\hline JJA & $-0.36 \pm 0.26$ & $0.35 \pm 0.14$ & $0.14 \pm 0.15$ \\
\hline SON & $0.39 \pm 0.27$ & $0.42 \pm 0.17$ & $0.29 \pm 0.16$ \\
\hline
\end{tabular}

\section{MLR of model HCHOv}

\begin{tabular}{|c|c|c|c|}
\hline & $\mathrm{HCHOv} \beta \beta_{-} \mathrm{T}_{\mathrm{s}}$ & $\mathrm{HCHOv} \beta \beta$ _SW & HCHOv_ $\beta$ P \\
\hline МАM & $\begin{array}{l}\text { (a) } 0.76 \pm 0.11 \\
\text { (b) } 0.77 \pm 0.13 \\
\text { (c) } 0.75 \pm 0.11\end{array}$ & $\begin{array}{l}\text { (a) } 0.20 \pm 0.09 \\
\text { (b) } 0.16 \pm 0.14 \\
\text { (c) } 0.20 \pm 0.12\end{array}$ & $\begin{array}{l}\text { (a) }-0.05 \pm 0.07 \\
\text { (b) }-0.09 \pm 0.08 \\
\text { (c) }-0.07 \pm 0.08\end{array}$ \\
\hline JJA & $\begin{array}{l}\text { (a) } 0.38 \pm 0.25 \\
\text { (b) } 0.58 \pm 0.23\end{array}$ & $\begin{array}{l}\text { (a) } 0.02 \pm 0.23 \\
\text { (b) }-0.04 \pm 0.27\end{array}$ & $\begin{array}{l}\text { (a) }-0.30 \pm 0.17 \\
\text { (b) }-0.21 \pm 0.13\end{array}$ \\
\hline
\end{tabular}




\begin{tabular}{|c|c|c|c|}
\hline & (c) $0.49 \pm 0.23$ & (c) $0.06 \pm 0.24$ & (c) $-0.27 \pm 0.16$ \\
\hline SON & $\begin{array}{l}\text { (a) } 0.64 \pm 0.15 \\
\text { (b) } 0.77 \pm 0.25 \\
\text { (c) } 0.72 \pm 0.19\end{array}$ & $\begin{array}{l}\text { (a) }-0.33 \pm 0.16 \\
\text { (b) } 0.16 \pm 0.22 \\
\text { (c) }-0.23 \pm 0.17\end{array}$ & $\begin{array}{l}\text { (a) }-0.02 \pm 0.09 \\
\text { (b) }-0.06 \pm 0.13 \\
\text { (c) }-0.02 \pm 0.11\end{array}$ \\
\hline \multicolumn{4}{|c|}{ Amazon } \\
\hline \multicolumn{4}{|c|}{ MLR of model GPP } \\
\hline & GPP_ $\beta \_T_{s}$ & GPP_ $\beta$ _PAR & GPP_ $\beta \_P$ \\
\hline МАM & $-0.13 \pm 0.50$ & $0.31 \pm 0.31$ & $0.41 \pm 0.37$ \\
\hline JJA & $-0.18 \pm 0.57$ & $0.18 \pm 0.32$ & $0.11 \pm 0.38$ \\
\hline SON & $-0.41 \pm 0.59$ & $0.20 \pm 0.22$ & $0.28 \pm 0.42$ \\
\hline \multicolumn{4}{|c|}{ MLR of model HCHOv } \\
\hline & HCHOv_ $\beta \_T_{s}$ & $\mathrm{HCHOv} \beta \beta$ SW & $\mathrm{HCHOv} \_\beta \_\mathrm{P}$ \\
\hline MAM & $\begin{array}{l}\text { (a) } 0.30 \pm 0.50 \\
\text { (b) } 0.42 \pm 0.39 \\
\text { (c) } 0.39 \pm 0.44\end{array}$ & $\begin{array}{l}\text { (a) }-0.05 \pm 0.36 \\
\text { (b) }-0.12 \pm 0.33 \\
\text { (c) }-0.14 \pm 0.33\end{array}$ & $\begin{array}{l}\text { (a) } 0.39 \pm 0.45 \\
\text { (b) } 0.20 \pm 0.45 \\
\text { (c) } 0.18 \pm 0.46\end{array}$ \\
\hline JJA & $\begin{array}{l}\text { (a) } 0.55 \pm 0.34 \\
\text { (b) } 0.77 \pm 0.37 \\
\text { (c) } 0.69 \pm 0.31\end{array}$ & $\begin{array}{l}\text { (a) }-0.04 \pm 0.29 \\
\text { (b) }-0.07 \pm 0.18 \\
\text { (c) }-0.07 \pm 0.23\end{array}$ & $\begin{array}{l}\text { (a) } 0.18 \pm 0.28 \\
\text { (b) } 0.23 \pm 0.28 \\
\text { (c) } 0.22 \pm 0.27\end{array}$ \\
\hline SON & $\begin{array}{l}\text { (a) } 0.41 \pm 0.36 \\
\text { (b) } 0.90 \pm 0.63 \\
\text { (c) } 0.78 \pm 0.59\end{array}$ & $\begin{array}{l}\text { (a) }-0.26 \pm 0.25 \\
\text { (b) }-0.34 \pm 0.22 \\
\text { (c) }-0.29 \pm 0.24\end{array}$ & $\begin{array}{l}\text { (a) } 0.15 \pm 0.59 \\
\text { (b) } 0.25 \pm 0.63 \\
\text { (c) } 0.23 \pm 0.64\end{array}$ \\
\hline
\end{tabular}



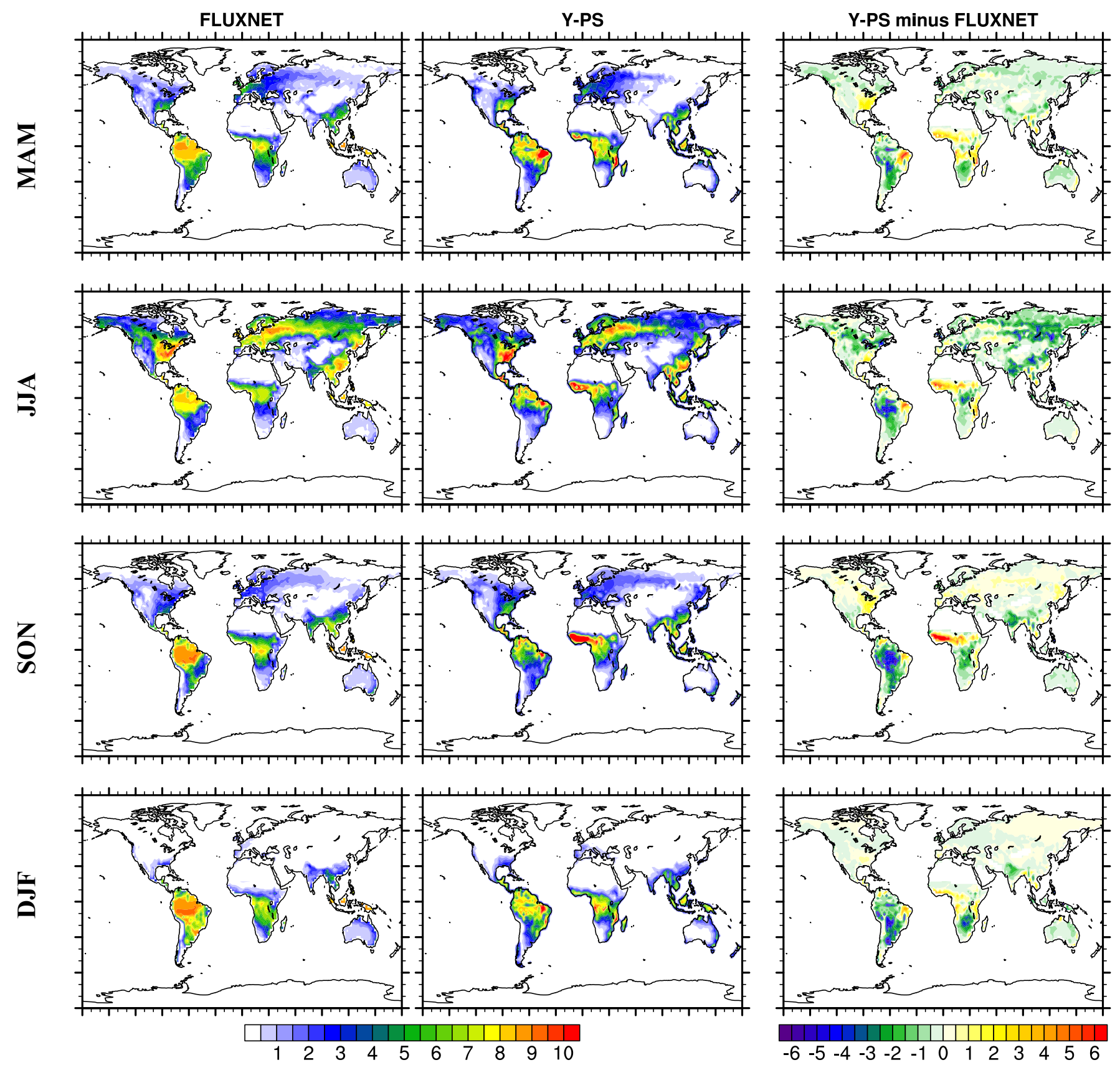

Figure S1. Seasonal averaged FLUXNET-derived GPP (first column), simulated GPP from NASA ModelE2-YIBs (using Y-PS algorithm, second column), and their difference (third column). The units are $\mathrm{g}[\mathrm{C}] \mathrm{m}^{-2} \mathrm{day}^{-1}$. GPP in Y-MEGAN and Y-MEGAN-SM are the same as GPP in Y-PS. 

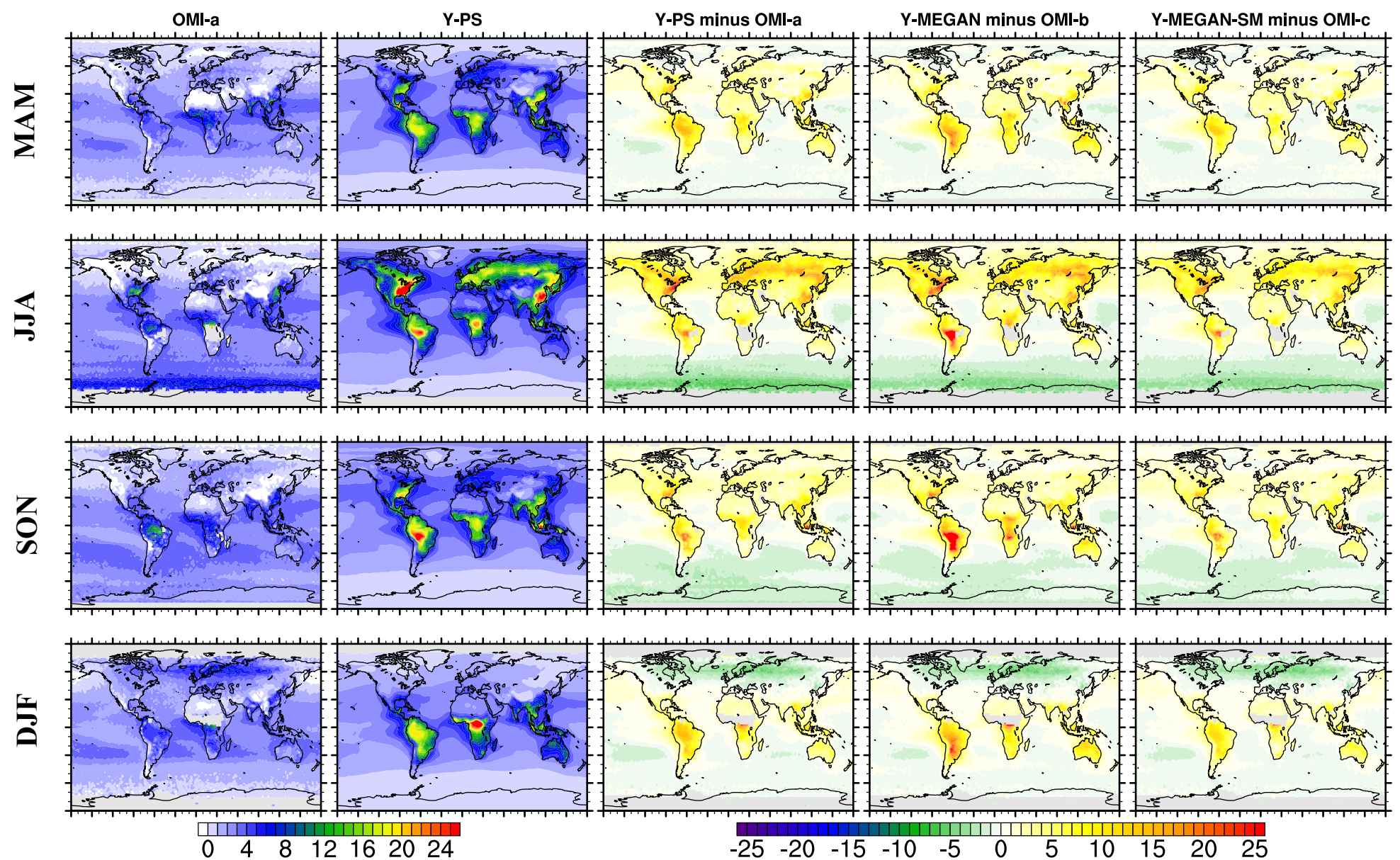

Figure S2. Seasonal averaged tropospheric HCHO columns from OMI-a (using air mass factors of YPS, first column), and simulated HCHO from NASA ModelE2-YIBs (using Y-PS algorithm, second column). The third to fifth columns represent the difference between simulated and OMI-retrieved HCHO columns. Third column: Y-PS simulation minus OMI retrieval using Y-PS AMFs (OMI-a); fourth column: Y-MEGAN simulation minus OMI retrieval using Y-MEGAN AMFs (OMI-b); fifth column: Y-MEGAN-SM simulation minus OMI retrieval using Y-MEGAN-SM AMFs (OMI-c). The units are $\times 10^{15}$ molecules $\mathrm{cm}^{-2}$. 
(a) MLR of model GPP

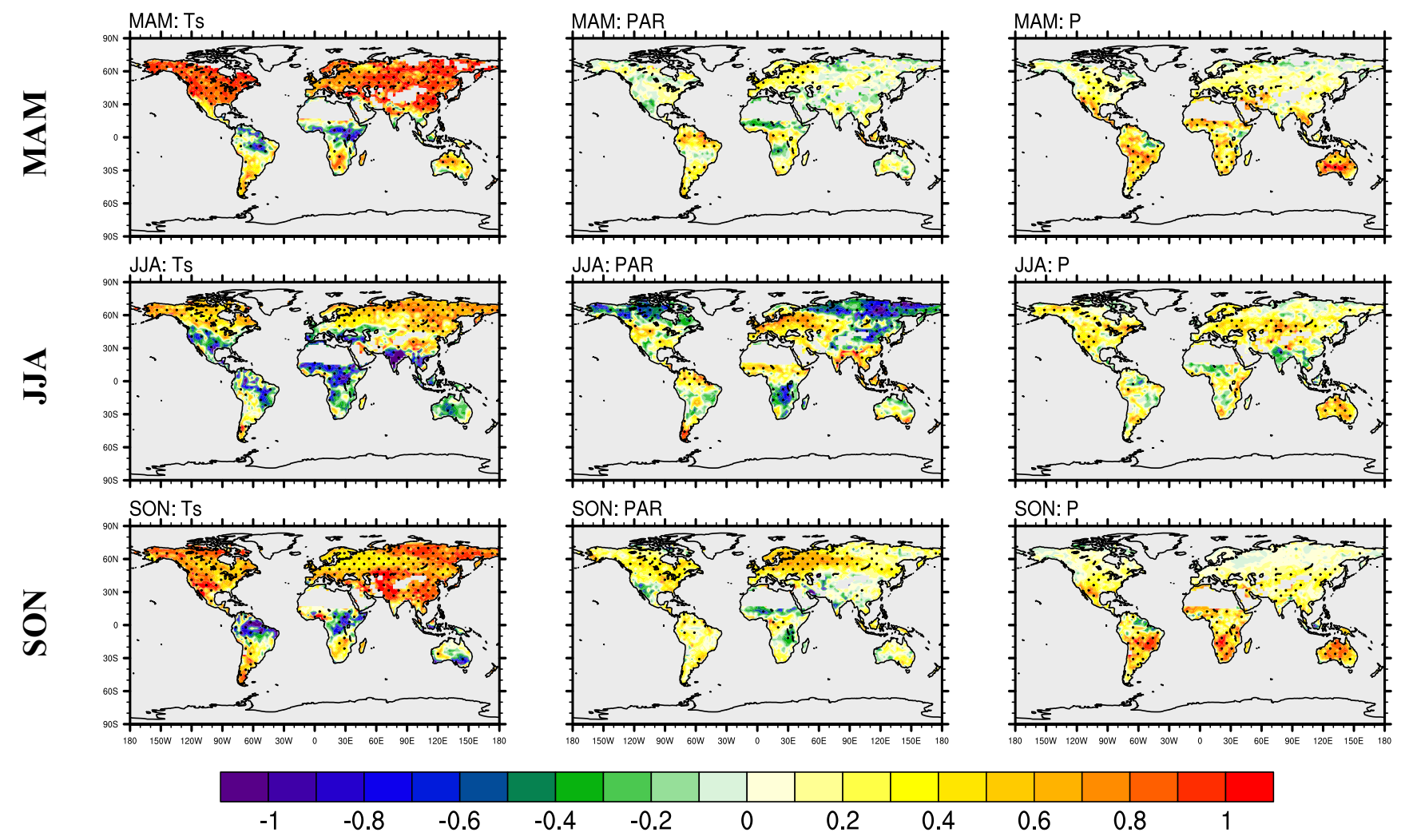

Figure S3. The covariance of model GPP in NASA ModelE2-YIBs with monthly mean surface temperature $\left(\mathrm{T}_{\mathrm{s}}\right)$, photosynthetically active radiation (PAR) and precipitation (P) in MAM (top), JJA (middle) and SON (bottom) from the MLR analysis. MLR is calculated using monthly data in nine model years. Significant regions $(\mathrm{p}<0.05)$ are shown with dotted shading. 


\section{(b) MLR of model HCHOv}
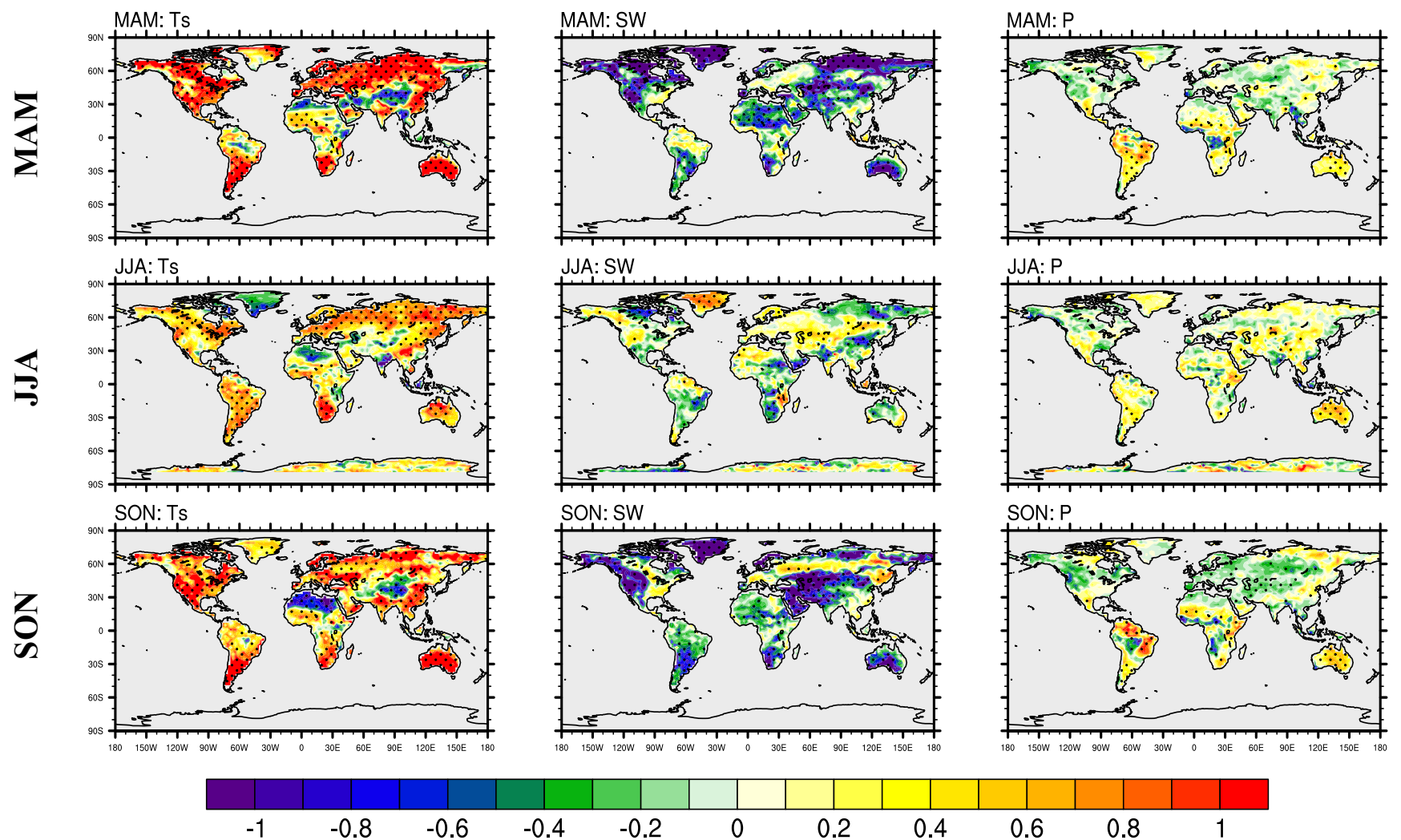

Figure S4. The covariance of model HCHOv in NASA ModelE2-YIBs (using Y-PS isoprene algorithm) with monthly mean surface temperature $\left(\mathrm{T}_{\mathrm{s}}\right)$, downward solar radiation $(\mathrm{SW})$ and precipitation $(\mathrm{P})$ in MAM (top), JJA (middle) and SON (bottom) from the MLR analysis. MLR is calculated using monthly data in nine model years. Significant regions $(p<0.05)$ are shown with dotted shading. 